\title{
SPECTROELECTROCHEMISTRY IN MELTS: APPLICATIONS TO MOLTEN CHLOROAIUMTNATES
}

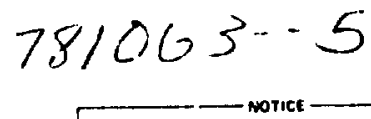

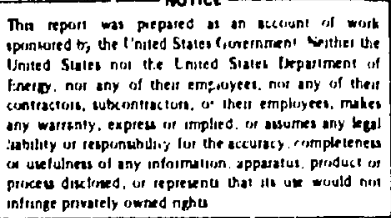

G. Mamantov, V.E. Norvell, and J.. Klatt**

Department of Chemistry, The University of Tennessee Knoxville, Tennessee 37916

*Analytical Chenistry Division, Oak Kidge Natjonal Iaboratory ${ }^{\dagger}$

$\because \ldots$ Oak Ridge, Temnessee 37830

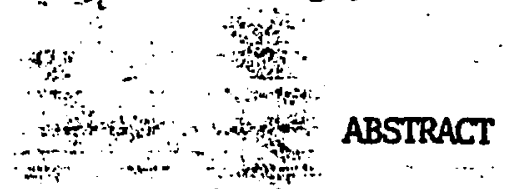

Spectroelectrochenistry is an effectjve approach to studies of redox chemistry in solutions. We have recently initiated UV-visible spectroelectrochenical studies in molten chloroalıminates ( $\mathrm{AlCl}_{3}-\mathrm{NaCl}$ mixtures) using a si]icon vidicon rapid-scan spectrometer. Flectrodes made from glassy carbon foam and metal grids are used in optically transparent thin layer cells. The solute species of interest are the oxidation products of sulfur and some of the Group IVB-VIB transition metal ions. In this paper the apparatus and the initial results are described.

\section{INIRODUCTION}

The use of spectroelectrochemistry as a tool for studying redox chemistry in solutions has developed rapidly over the last several years (1). This technique yields simultaneous spectral and electrochemical information useful in the elucidation of mechanisms of redox reactions. By using appropriate experimental designs, short-lived intermediate species, which may be undetectable electrochemically, can be studied.

The transmission mode spectroelectrochemical experiment involves the use of an optically transparent elsctrode (OTE), i.e. an e] ectrode which is transparent in the spectral region of interest. Radiation of the desired wavelengths is passed through the solution and the OTE where a portion is absorbed by the solute species. The attenuated radiation is then measured to give a spectrum. Spectroelectrochemistry most commonly involves the UV-visible-IR spectral regions, but it has been applied to ESR, MMR and mass spectrometry as well (1).

† Operated for the U.S. Department of Energy by Union Carbide Corporation under Contract W-7405-eng-26.

By acceptance of this article, the publisher or recipient acknowledges the U.S. Government's right to retain a non-exclusive, royaltyfree license in and to any copyright covering the article. 
We are currently developing UV-visible spectroelectrochemical techniques for studying redox systems in molten chloroaluminates (mixtures of $\mathrm{AlCl}_{3}$ and alkali halides). Solute chemistry in these melts is quite dependent on the melt acidity (2-4). The acid-base properties of the chloroaluminate melts near the $1: 1 \mathrm{AlCl}_{3}-\mathrm{NaCl}$ mole ratio can be described by the equilibrium (5-9)

$$
2 \mathrm{AlCl}_{4}{ }^{-}=\mathrm{Al}_{2} \mathrm{CI}_{7}{ }^{-}+\mathrm{Cl}^{-}
$$

$\mathrm{AlCl}_{4}^{-}$is the predominant anion in the equimolar $\mathrm{AlCl}_{3}-\mathrm{NaCl}$ melt. As the acidity is increased, $\mathrm{Al}_{2} \mathrm{Cl}_{7}^{-}$becomes more abundant (5-9).

To date we have examined by spectroelectrochemistry the reduction of niobium $(V)$ and the oxidation of sulfur in chloroaluminate melts. The use of OTE's to study species in melts spectroelectrochemically has not been reported previously.

\section{EXPERTMENTAI}

A block diagram of the spectrometer/data acquisition system used to carry out spectroelectrochemical experiments is shown in Figure 1. The spectrometer is a silicon-vidicon based rapid-scan spectrometer (RSS) which is controlled by the PDP-8/I minicomputer. To obtain an absorption spectrum of a sample, white light is passed through the sample and into a polychromator where it is dispersed by a grating. A $400 \mathrm{~nm}$ wide segment of this spectrum is directed across the face of the vidicon detector, where it is read as light intensity vs. wavelength by an electron beam. The sweep frequency of this beam can be adjusted so that spectra may be acquired at time intervals varying from $10 \mathrm{msec}$ to $5 \mathrm{sec}$. Since the spectrometer operates in a singlebeam mode, a $100 \%$ transmission spectrum (with no sample in the beam) is also acquired and the absorbance spectrum is calculated using the computer. Spectra are stored either on disk or cassette tape. An absorption spectrum can be viewed either on a CRT display, or displayed on an $X-Y$ recorder. A potentiostat is also interfaced to the system; this makes it possible to synchronize the start of spectral data acquisition with the initiation of the electrochemical experiment as well as to simultaneously acquire and store both spectral and electrochemical data. A more detailed description of the spectrometer and the computer interface system is available (10).

A typical cell used to carry out molten salt spectroelectrochemical experiments is illustrated in Figur: 2. The optically transparent electrode consists of a piece of porous glassy carbon (11), a platinum screen or a tungsten grid. The OlE is inserted into the quartz cuvette, the pathlength of which ranges from $0.25 \mathrm{~mm}$ tc $2.00 \mathrm{~mm}$, and the OTE assembly is held in place by a Cajon vacuum fitting. The counter electrode is a platinum foil electrode and the reference electrode is an aluminum wire in a separate fritted compartment. 
Other electrodes, not shown for clarity, include a platinum or tungsten wire working electrode for cyclic voltanmetry, and an extra platinum foil electrode. The melt is added via a filling tube (not shown) in the top of the cell which is then sealed under vacuum. The cell. is molmited in a suspension assembly by means of the support ring, and this assembly is then lowered into an optical furnace. The furnace consists of a glass tube wrapped with a ni.chrome heating element, and contains two quartz windows through which spectra are taken. The furnace temperature is controlled by using a variable voltage transformer. A tungsten lamp and a xenon arc lamp serve as light sources.

\section{SPECTROELFCTROCHEMICAL STUDY OF \\ THE REDUCIION OF NIOBIUM (V)}

The redox chemistry of transition metals in Groups IVB-VIB in chloroaluminate melts is umusual because of the tendency to form metal clusters in which the metal exists in an unusually low oxidation state $(2,4,12-14)$. The electrochemical reduction of $\mathrm{Nb}(\mathrm{V})$ in both acidic (mole $: \mathrm{AlCl}_{3}>50$ ) and basic (mole : $\mathrm{AlCl}_{3}<50$ ) chloroaluminates has been previously reported (4). Potentiometric and spectroscopic studies of $\mathrm{Nb}(\mathrm{V})$ in $\mathrm{AlCl} 3-\mathrm{KCl}$ melts have also been performed (15). In basic melis the first step of the reduction of the bright-yellow $\mathrm{Nb}(\mathrm{V})$ results in the formation of purple $\mathrm{Nb}$ (IV). The spectroelectrochemistry of this reduction was studied at a Pt screen OTE in a NaCl-saturated (basic) melt at $225^{\circ} \mathrm{C}$. Figure 3 illustrates the spectra obtained during the course of the reduction. At $t=0 \mathrm{sec}$, an absorption band at $300 \mathrm{~mm}$ due to $\mathrm{Nb}(\mathrm{V})$ is observed. Hollowing a potential step to the diffusion plateau of the first reduction wave, two new absorption bands appear at $275 \mathrm{~mm}$ and $\sim 350 \mathrm{~mm}$. Previous spectra of $\mathrm{Nb}(\mathrm{TV})$ obtained in this melt (14), in solid phase (16), and in another solvent (17) show bands near $285 \mathrm{~nm}$ and $325 \mathrm{~nm}$, plus other lower wavelength bands. The reported band positions vary. by as much as 10-15 nm. Figure 4 shows a thin-layer coulogram of this reduction calculated from chronoamperometric data obtained simultaneously with spectral data. Th: charge value obtained from this curve yields an $n$-value of 0.99 , thus confirming a simple electrochemical reduction.

In acidic melts, the reduction of $\mathrm{Nb}(\mathrm{V})$ proceeds through an ECE mechanism to produce a $\mathrm{Nb}$ (III) species (4) as shown below:

$$
\begin{aligned}
& \mathrm{Nb}(\mathrm{V})+\mathrm{e} \rightleftharpoons \mathrm{Nb}(\mathrm{IV}) \\
& 2 \mathrm{Nb}(\mathrm{IV}) \rightleftharpoons \mathrm{Nb}_{2}^{8+} \\
& \mathrm{Nb}_{2}^{8+}+2 \mathrm{e} \rightleftharpoons \mathrm{Nb}_{2}{ }^{6+}
\end{aligned}
$$

This reduction was studied spectroelectrochemically in an acidic melt $\left(\mathrm{AlCl}_{3}-\mathrm{NaCl} 63-37\right.$ mole $\%$ ) at $225^{\circ} \mathrm{C}$, and the resulting spectra are shown in Figure 5. The $\mathrm{Nb}(\mathrm{V})$ band at $300 \mathrm{~nm}$ disappears as the reduction is carried out, and no new bands are observed. The slight increase 
in absorbance seen at the longer wavelengths is probably due to the formation of a precipitate containing $\mathrm{Nb}$ (III) (14). Because this precipitate apparently was deposited on the screen OIE, it could be reoxidized completely to $\mathrm{Nb}(\mathrm{V})$, as indicated by the reappearance of the band at $300 \mathrm{~nm}$. Thiri-layer coulometry carried out simultaneously with spectral acquisition gave an n-value of 2.2.

\section{SPECTROELECTROCHEMICAL STUDY OF SULFUR OXIDATION}

The electrochemistry of sulfur in molten chloroaluminates is of considerable importance to the development of a molten salt battery using a sod: um anode and positive oxidation states of sulfur as the cathode $(18,19)$; it has been investigated in both basic and acidic melts $(20-22)$. Because sulfur can be oxidized to higher oxidation states in acidic melts, its chemistry in these melts is of greater importance to the battery work. In acidic $\mathrm{AlCl}_{3}-\mathrm{NaCl}$ melts sulfur is oxidized in three steps, the final product being S(IV) as indicated by voltarmetry and controlled-potential coulometry (22). Both Raman (23) and potentiometric $(24,25)$ studies have indicated that $S(I V)$ is present as $\mathrm{SCl}_{3}{ }^{+}$.

We are using spectroelectrochemistry to study further the mechanism of the oxidation of sulfur in acidic chloroaluminates. By oxidizing elemental sulfur in the melt to $S(I V)$, at least five intermediate oxidation states can be produced $(24,25)$. Several of these species have characteristic absorption maxina which can be used to ascertain the species present as a function of the potential applied to the OTE.

Elemental sulfur was dissolved in an acidic chloroaluminate melt ( $\mathrm{AlCl}_{3}-\mathrm{NaCl}$ 63-37 mole $\%$ ); this solution was studied spectroelectrochemically at platinum and carbon OTE's at $225^{\circ} \mathrm{C}$. Tiin-layer coulometry was carried out on the first oxidation wave by holding the potential of a Pt OTE at $+1.65 \mathrm{~V}$. N-values ranging from 0.14 to 0.16 were obtained. These results agres with those obtained through exhaustive bulk coulometry (22). An n-value of 0.125 would correspond to the formation of $\mathrm{S}_{16^{2+}}{ }^{+}$(or $\mathrm{S}_{8}{ }^{+}$), while an $\mathrm{n}$-value of $(.25$ would indicate formation of $\mathrm{S}_{3}{ }^{2+}$. The intermediate value suggests that a mixture of these species is formed. The spectra shown in Figure 6 , obtained at a carbon OTE, substantiate this supposition. As the oxidation takes place, three absorption bands appear approximately simultaneously at $16600 \mathrm{~cm}^{-1}$ $(600 \mathrm{~nm}), 13700 \mathrm{~cm}^{-1}(730 \mathrm{nn})$ and $10200 \mathrm{~cm}^{-1}$ (980 nm). The latter two bands achieve a maximm absorbance after about four minutes and begin to decrease as the first band continues to increase. This can be seen clearly from the absorbance-time profiles illustrated in Figure 7. According to preyiously published work $(24,25)$, the $600 \mathrm{~nm}$ band is attributed to $\mathrm{S}_{8}{ }^{2+}$ and the $730 \mathrm{~mm}$ and $980 \mathrm{~mm}$ bands are due to $\mathrm{S}_{16^{2+}}{ }^{2+}$ This $f_{1}$ rst oxidation step then produces a mixture of $\mathrm{S}_{16^{2+}}$ (or $\mathrm{S}_{8}^{+}$) and $\mathrm{S}_{8}{ }^{2+}$. Marassi et al. (22) have proposed mechanisms involving chemical reactions which could account for these results. 
The spectra shown in Figure 8 were obtained by stepping the potential of the carbon OTE from $1.65 \mathrm{~V}$ (plateau of the first wave) to $1.85 \mathrm{~V}$ (just past the plateau of the second wave). The band at $13700 \mathrm{~cm}^{-1}$, due to $\mathrm{S}_{16}{ }^{2+}$ (or $\mathrm{S}_{8}^{+}$) inmediately vanishes while the band at $16600 \mathrm{~cm}^{-1}$ $\left(\mathrm{S}_{8}{ }^{2+}\right)$ initially increases. This band then slowly disappears as $\mathrm{S}_{8}{ }^{2+}$ is oxidized to $\mathrm{S}(\mathrm{I})$. In a similar experiment caried out at a $\mathrm{Pt}$ screen OTE, but recording spectral data at shorter wavelengths, bands at ca. $26300 \mathrm{~cm}^{-1}(380 \mathrm{~nm})$ and $\sim 31000 \mathrm{~cm}^{-1}(323 \mathrm{~nm})$ appeared as the oxidation proceeded. At least one and perhaps both of these bands can be attributed to the formation of $S(I)$ (as $S_{2}{ }^{2+}$ ) (25). The third sulfur oxidation wave is not very interesting for spectroelectrochemical study because the S(IV) product does not exhibit any absorption in the visible region $(25)$.

\section{CONCLUSION}

We have demonstrated that spectroelectrochemistry can be carried out successfully in melts using optically transparent electrodes. The correlation of the spectral data with the electrochemical results has proven very helpful in determining what species are formed during the reduction or oxidation, thereby yielding insight into the mechanisms of the electrochemical processes in melts.

\section{ACKNOWLEDGENENTS}

Molten salt research at the University of Tennessee is supported by the National Science Fourdation Grant CHE 77-21370, and the Department of Energy, Contract EY-76-S-05-5053. V.E. Norvell holds an Oak Ridge Associated Universities Fellowship.

\section{REFERENCES}

1. W.R. Heineman, Anal. Chen., 50, 390A (1978), and references therein.

2. G. Mamantov and R.A. Osteryoung, in Characterization of Solutes in Nonaqueous Solvents , G. Mamantov, ed., Plenum Press, New York, N.Y., 1978, pp. 223-249.

3. G. Torsi, K.W. Fung, G.M. Begun, and G. Mamantov, Inorg. Chem., 10, 2285 (1971).

4. G. Ting, K.W. Fung, and G. Mamantov, J. Electrochem. Soc., 123, 624 (1976).

5. B. Tremillon and G. Letisse, J. Electroanal. Chem., 17, 371 (1968).

6. G. Torsi and G. Mamantov, Inorg. Chem., 10, 1900 (1971).

7. G. Torsi and G. Mamantov, ibid., 11, 1439 (1972).

8. A.A. Fannin, L.A. King, and T.W. Seegmiller, J. Electrochem. Soc., 119,801 (1972).

9. L.G. Boxa11, H.L. Jones, and R.A. Osteryoung, ibid., 120, 223 (1973). 
10. L.N. Klatt, J. Chromatogr. Sci., in press.

11. V.E. Norveil and G. Mamantuv, Anal. Chem., 49, 1470 (1977).

12. D.L. Brotherton, Ph.D. Dissertation, University of Tennessee, Knoxville, TN, 1974.

13. L.E. MCCurry, G. Mamantov, N.J. Bjerrum, F.W. Poulsen, and J.H. von Barner, in Proceedings of the Symposium on High Temperature Metal Halide Chemistry, D.L. Hildebrand and D.D. Cubicciotti, eds., The Electrochemical Society, Princeton, New Jersey, 1978, pp. $421-425$.

14. L.E. McCurry, Ph.D. Dissertation, University of Tennessee, Knoxville, TN, 1978.

15. J.H. von Barner, N.J. Bjerrum and G.P. Smith, Acta Cnem. Scand. $A$, to be published.

16. G.W.A. Foules, D.J. Tidmarsh, and R.A. Walton, Inorg. Chem., $\underline{8}$, 631 (1969).

17. S.M. Horner and S.Y. Tyree, Inorg. Nucl. Chem. Letters, 1, 43 (1965).

18. G. Mamantov and R. Marassi, U.S. Patent 4,063,005, December 13, 1977.

19. G. Mamantov, R. Marassi, J.P. Wiaux, S.E. Springer and E.J. Frazer, in Proceedings of the Symposium on Load Leveling, N.P. Yao and J.R. Selman, eds., The Electrochemical society, Princeton, New Jersey, 1977, pp. 379-383.

20. R. Marassi, G. Mamantov and J.Q. Chambers, J. Electrochem. Soc., 123,1128 (1976).

21. $\overline{K . A}$. Paulsen and R.A. Osteryoung, J. Am. Chem. Soc., 98, 6636 (1976).

22. R. Marassi, G. Mamantov, M. Matsunaga, S.E. Springer, and J.P. Wiaux, J. Electrochem. Soc., in press.

23. F.W. Poulsen, R. Huglen and G. Mamantov, unpublished work.

24. N.J. Bjerrum, in Characterization of Solutes in Nonaqueous Solvents, G. Mamantov, ed., Plenum Press, New York, N.Y., 1978, pp. 251-271.

25. R. Fehrmann, N.J. Bjerrum and F.W. Poulsen, Inorg. Chem., 17, 1195 (1978). 


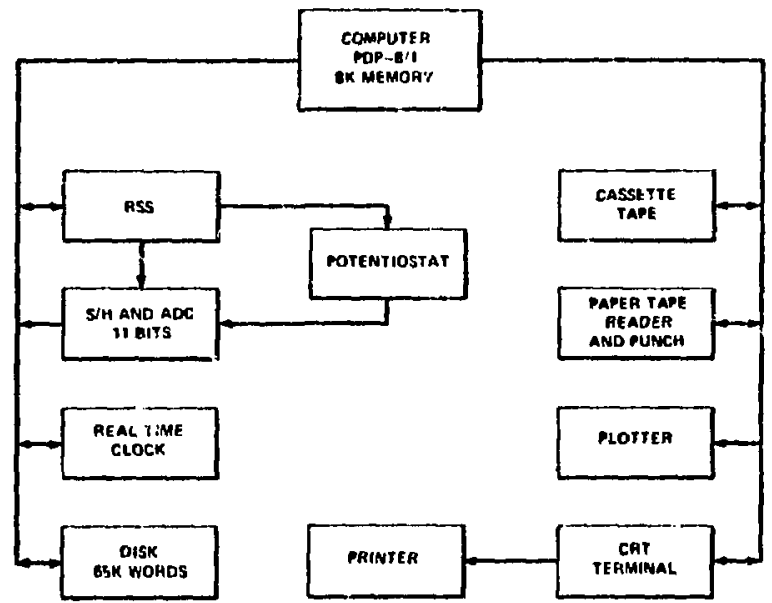

Figure 1. Block diagram of the system used for spectrodectrochemical experiments

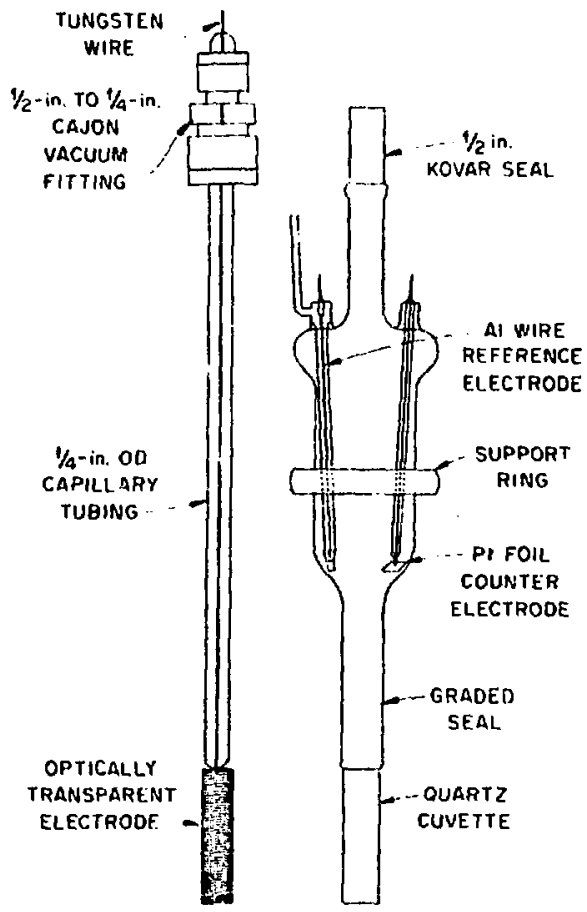

Figure 2. Typical spectroelectrochemical cell used in the molten salt studies. The reference electrodo is isolated from the bulk meit by a porous ceramic frit 


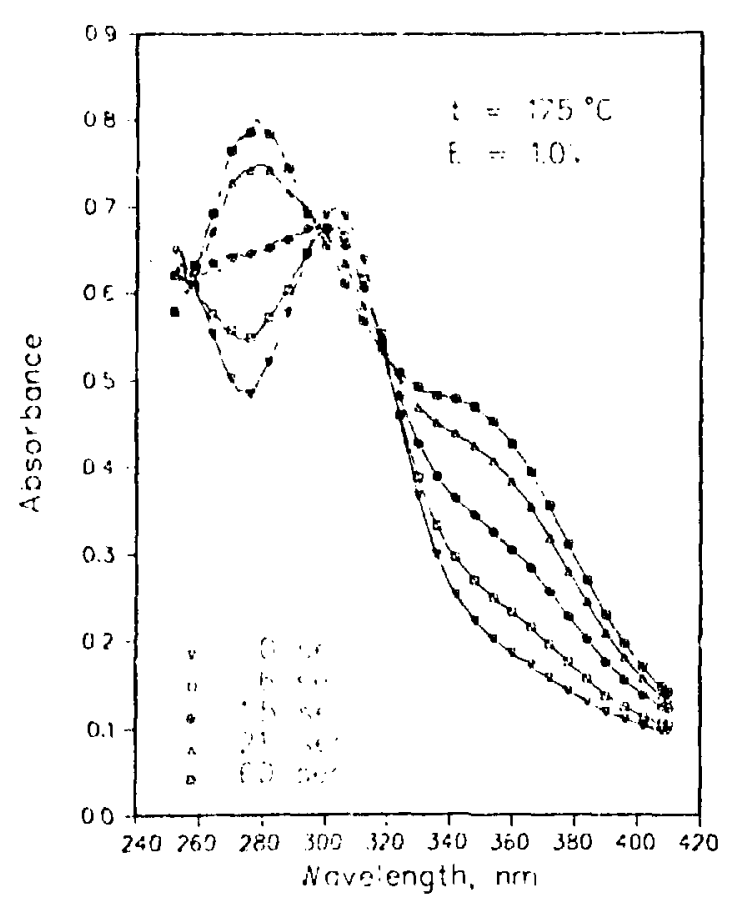

OARLL DNC TO9S18

Figure 3. Spectra obtained during the reduction of $\mathrm{Nb}(\mathrm{V})$ in the NaCl-saturated chloroaluminate meit. Potential stepped from $1.5 \%$ to $1.0 \mathrm{~V}$ vs. the All!II)/AI reference electrode in the $\mathrm{NaCl}$-saturatad melt.

OTE: Pt scrien. Pathlengih: $0.25 \mathrm{~mm}$ Conc. $\mathrm{Nb}(\mathrm{V}): 0.0015$ molal

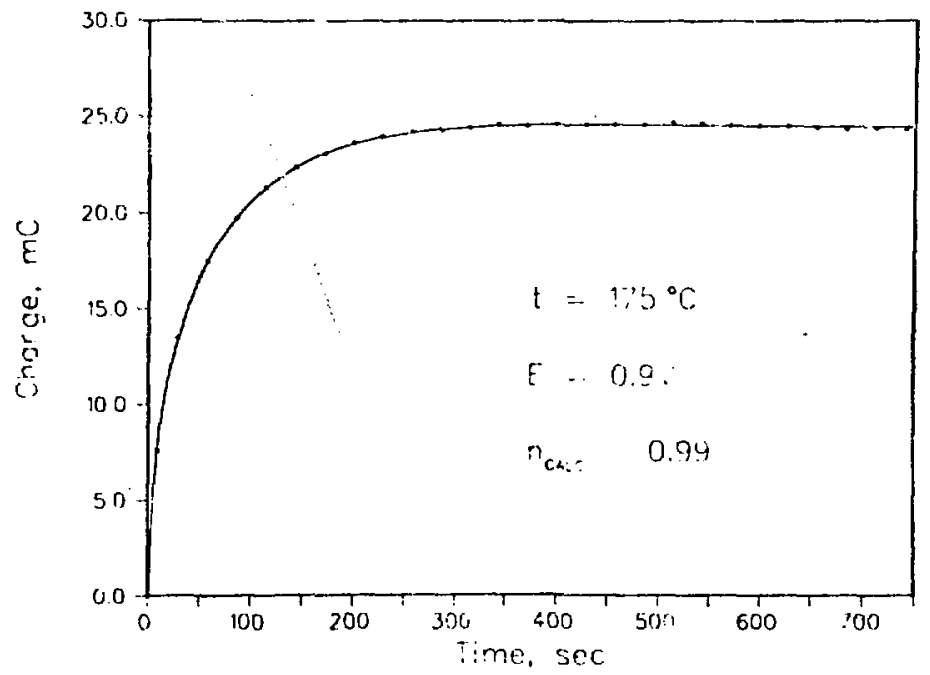

Figure 4. Charge vs. time plot for the thin-layer coulometric reduction of $\mathrm{Nb}(\mathrm{V})$ in the $\mathrm{NaCl}$-saturated chloroaluminate melt. Potential stepped from $1.5 \mathrm{~V}$ to $0.9 \mathrm{~V}$ vs. the Al(III)/Al reference electrode in the NaCl-saturated melt. OTE: Pt screen 


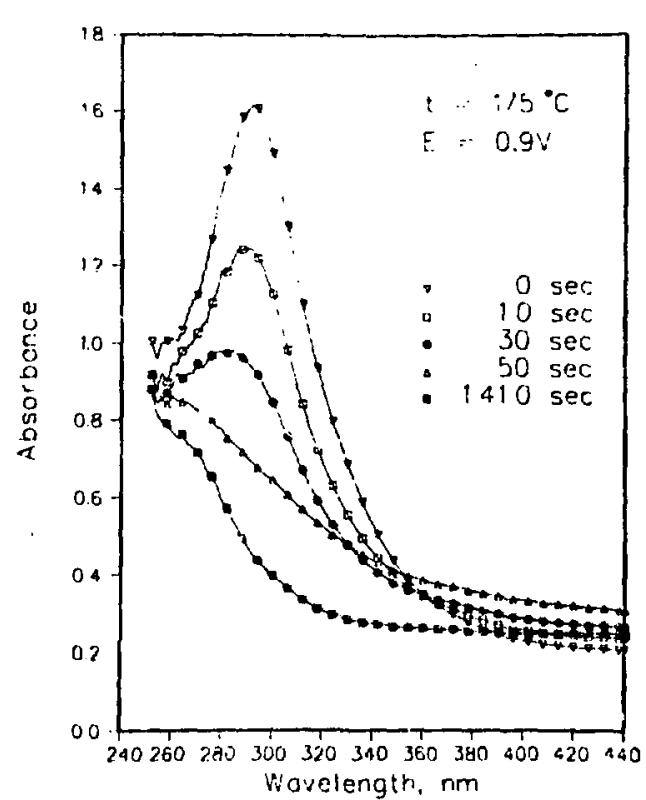

ORAL OWG TESIS

Figure 5. Spectra obteined during the reduction of $\mathrm{Nb}(\mathrm{V})$ in $\mathrm{AlCl}_{3}-\mathrm{NaCl}(63-37$ mole \%) intit. Potential stepped from 1.5V to $0.9 \mathrm{~V}$ vs. the Al(III)/AI reference olsctrods in the $63-37$ molt.

OTE: Pt screen. Pathlength: $0.25 \mathrm{~mm}$ Conc. Nb(V): $0.0036 \mathrm{molal}$

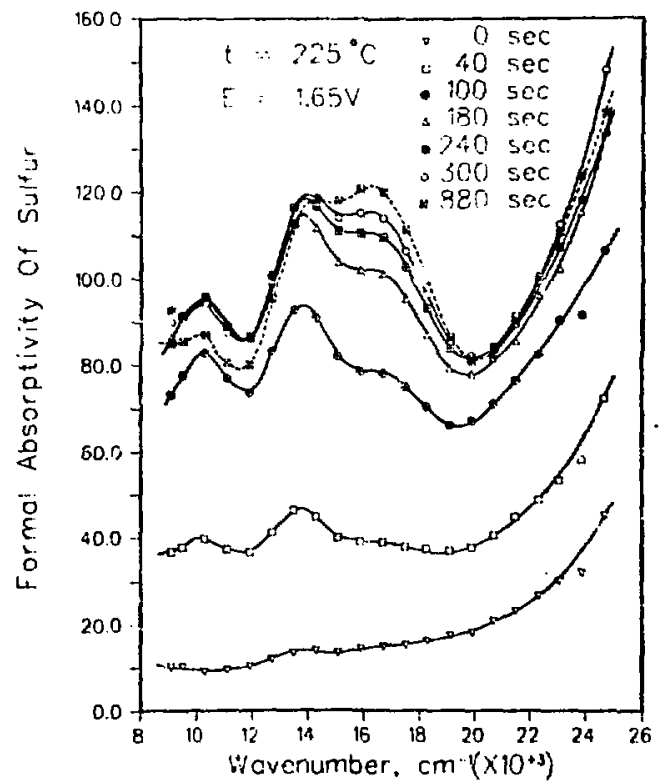

Figure 6. Spectra obtained during the oxidation of sulfur at a glsssy carbon OTE in the $\mathrm{AlCl}_{3}-\mathrm{NaCl}$ (63-37 mole \%) melt. Potential stepped from 1.3V to $1.65 V$ vs. the AllIII)/Al reference electrode in the 63-37 moit. Conc. S: 0.013 moill 
ORNL OLV 19.650

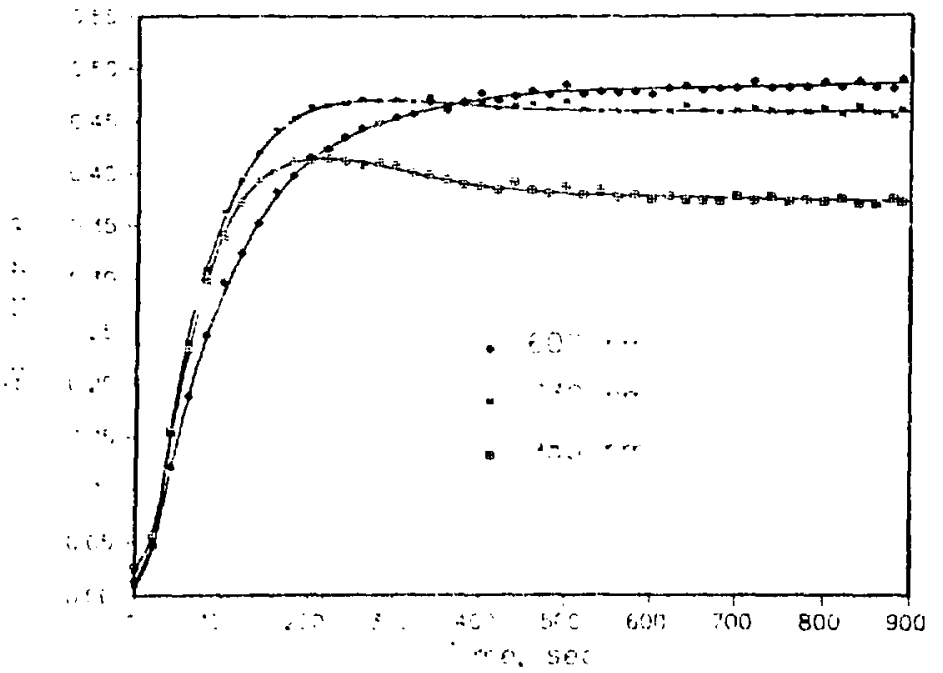

Figure 7. Atsorbance vs. time plots for the three absorbance bands shown in Figure 6 . Pathlength: $2.0 \mathrm{~mm}$

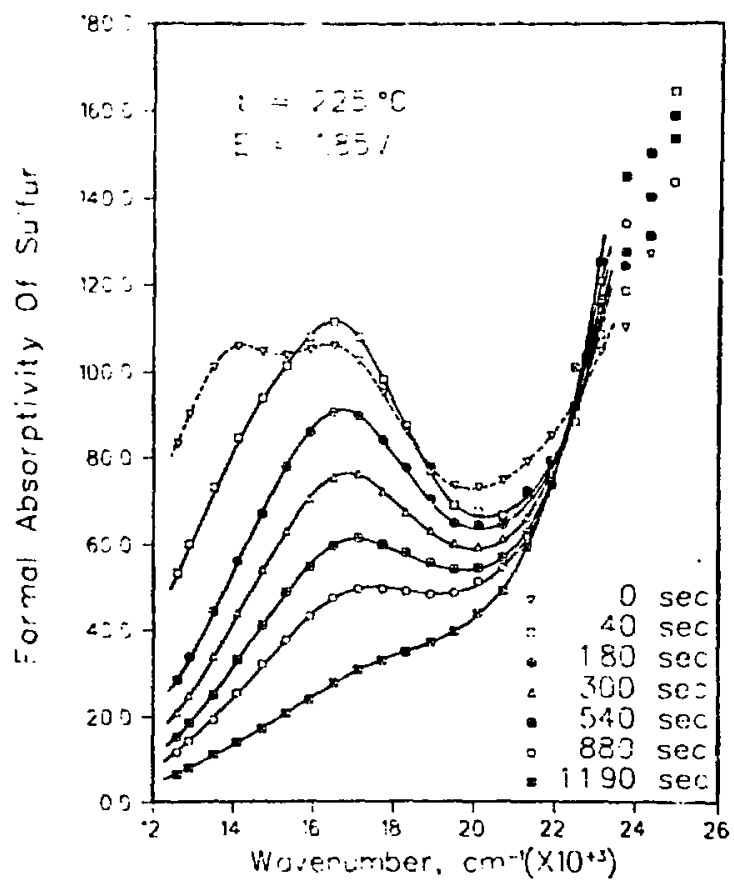

Figure 8. Spectra obtained during the oxidation of sulfur at a glassy carbon OTE in the $\mathrm{AlCl}_{3}-\mathrm{NaCi}$ (63-37 mole \%) melt. Potential stepped from $1.65 \mathrm{~V}$ to $1.85 \mathrm{~V}$ vs. the Al(III)/Al reference electroje in the 63.37 melt. Conc. S: 0.013 molal 